\title{
PERKEMBANGAN KEABSAHAN KONTRAK ELEKTRONIK DI INDONESIA
}

\author{
Saparyanto $\bowtie$ \\ Magister Ilmu Hukum Universitas Sebelas Maret \\ Sapar.yanto96@gmail.com
}

\begin{abstract}
Electronic contract is a contract that caused due to the development of technology and information, which is selling and buying transactions began to be done through online whether via website nor social media. Due to the process of making electronic contract is unlike conventional agreement, a clear regulation about the terms of contract validity and about the legal force of electronic contracts is required. Research method that used in writing this paper is the normative method. The regulation about terms of contract validity and about the legal force of electronic contracts in Indonesia are still uncertain. In addition, electronic contracts are often made in the form of standard contracts. Standard clause is often made based on the need of the seller by abandoning the prevailing laws and regulations which would impact on the legal protection of the consumer
\end{abstract} Keywords: Terms of Electronic Contracts V alidity; E-Commerce Transactions; Law of Obligations.

Kontrak elektronik merupakan kontrak yang timbulkan akibat perkembangan teknologi dan informasi, di mana transaksi jual beli mulai dilakukan melalui media elektronik atau online. Karena pembuatannya tidak seperti perjanjian pada umumnya yang konvensional, maka diperlukan pengaturan yang jelas mengenai syarat sahnya dan kekuatan hukum dari kontrak elektronik. Metode penelitian yang digunakan dalam karya ilmiah ini adalah metode normatif. Ketentuan mengenai syarat sahnya serta kekuatan hukum dari kontrak elektronik dalam peraturan perundangundangan yang mengatur mengenai transaksi elektronik masih mengalami ketidakpastian. Selain itu kontrak elektronik seringkali dibuat dalam bentuk kontrak baku. Ketentuan klausula baku dalam kontrak elektronik seringkali dibuat berdasarkan keinginan pelaku usaha tanpa memperhatikan peraturan perundang-undangan yang berlaku dan hal ini berdampak pada perlindungan hukum terhadap konsumen.

Kata Kunci: Keabsahan; Kontrak Elektronik; Transaksi E-Commerce; Hukum Perikatan.

\section{INTRODUCTION}

Keberadaan peradaban dunia saat ini dibuat berubah dengan adanya perkembangan teknologi yang begitu pesat dari waktu ke waktu. ${ }^{1}$ Perkembangan teknologi informasi telah

\footnotetext{
${ }^{1}$ Man Suparman Sastrawidjaja. (2002). Perjanjian Baku Dalam Aktivitas Dunia Maya,. Jakarta: elips . 
berhasil menciptakan infrastruktur informasi baru, tersedianya layanan akses data internet yang memberikan efesensi, alternatif ruang dan pilihan yang tanpa batas kepada penggunanya untuk melakukan banyak kegiatan diantaranya bisnis. Daya tarik ini yang menjadikan banyak pengguna transaksi bisnis konvensional kemudian beralih menggunakan sistem elektronik. Sebagai contoh telepon genggam untuk berkomunikasi dalam jarak yang jauh, robot diciptakan untuk membantu pekerjaan rumah, internet sebagai koneksi ke berbagai penjuru dunia dan sebagainya. Perkembangan ekonomi di Indonesia melaju cepat dalam beberapa tahun belakangan ini. Perkembangan ekonomi yang didampingi perkembangan teknologi yang begitu pesat maka banyak kegiatan ekonomi di Indonesia dilakukan berbasis teknologi pula ${ }^{2}$. Salah satu bidang yang membawa dampak yang sangat besar bagi masyarakat luas adalah perdagangan secara elektronik atau ecommerce ${ }^{3}$.

Saat ini, Indonesia telah memiliki Undang-Undang Nomor 11 Tahun 2008 tentang Informasi dan Transaksi Elektronik (UU ITE) yang diundangkan sejak 21 April 2008 lalu. Teknologi sekarang ini dapat dikatakan mengalami perkembangan pesat. Teknologi informasi dan elektronik merupakan salah satunya. Demikian pula di Indonesia, hampir semua hal mengenai informasi dan elektronik tidak lepas dari pengaruh teknologi modern yang semakin hari semakin berkembang.Perkembangan ini telah mengubah pola pikir dan kehidupan masyarakat di Indonesia, hal-hal yang tadinya dilakukan melalui cara yang dapat dikatakan tradisional, saat ini bisa dilakukan dengan memanfaatkan perkembangan teknologi 4 .

Contohnya bisnis online yang melakukan transaksi jual beli barang melalui sebuah aplikasi online, pengadaan alat-alat canggih tertentu guna memproduksi barang yang menghasilkan nilai ekonomi. Perjanjian adalah salah satu aspek penting dalam bisnis yang dilakukan oleh individu dengan individu maupun individu dengan kelompok ${ }^{5}$

Model kontrak baku biasanya digunakan oleh beberapa website-website untuk beberapa akun media sosial yang menggunakan kesepakatan bersama melalui pesan singkat, namun terkadang penjual menjadi pihak yang mendominasi pembuatan kontrak tersebut.Berdasarkan Pasal 1320 Kitab Undang-Undang Hukum Perdata, syarat - syarat sahnya perjanjian adalah adanya kesepakatan antara para pihak, kecakapan hukum, adanya itikad baik dan adanya objek tertentu. Jika membandingkan dengan bentuk kontrak atau perjanjian elektronik yang beredar selama ini dengan ketentuan Pasal 9 Undang-Undang Nomor 11 Tahun 2008 tentang Informasi dan Transaksi Elektronik, maka terjadi kekaburan norma dalam pengaturan mengenai bentuk pasti dari kontrak elektronik serta syarat kontrak yang seperti apa yang dimaksud oleh ketentuan ini ${ }^{6}$.

\footnotetext{
${ }^{2}$ Manap, M. A. (2018). Kontrak Elektronik: Isu dan Penyelesaian Undang-Undang . Journal of law and goverment, 64 .

${ }^{3}$ Latumahina, R. E. (2015). Aspek-aspek Hukum Dalam Transaksi Perdagangan Secara . Jurnal GEMA AKTUALITA , 43.

${ }^{4}$ Arista, O. (2013). EFEKTIVITAS UNDANG-UNDANG INFORMASI DAN TRANSAKSI ELEKTRONIK DI INDONESIA. UNS Journal of Law, 139

5 ekarini, M. A. (2014). "Eksistensi Asas Kebebasan Berkontrak Berkaitan Dengan Klausula Eksonerasi Dalam Perjanjian Baku. Kertha Semaya: Journal of law, 3.

${ }^{6}$ Putri, W. S. (2018). KEABSAHAN KONTRAK ELEKTRONIK DALAM TRANSAKSI ECOMMERCE DITINJAU DARI HUKUM PERIKATAN. JURNAL UNDIKNAS, 301.
}

(c) Author(s). This work is licensed under a Creative Commons Attribution-NonCommercial-ShareAlike 4.0 International License. Published by Postgraduate Program, Master of Laws, Faculty of Law, Universitas Sebelas Maret, Indonesia 
Transaksi elektronik yang dilakukan melalui website dengan domain yang telah didaftarkan, lebih mudah untuk menentukan atau membuktikan bahwa kontrak elektronik tersebut memang benar disetujui oleh kedua belah pihak, namun bagaimana jika mereka melakukan transaksi elektronik menggunakan media sosial seperti instagram, facebook, line atau whatsapp? Maka akan sangat sulit membuktikan apakah sungguh-sungguh kedua belah pihak memang menyetujui perjanjian tersebut.

\section{RESULTS \& DISCUSSION}

\section{EXPANSION OF OBJECTS OF DISPUTE IN ADMINISTRATIVE JUSTICE}

\section{Keabsahan Kontrak Elektronik dalam Undang-Undang Nomor 11 Tahun 2008 tentang Informasi dan Transaksi Elektronik serta Dilihat Dari Perspektif Hukum Perikatan}

Kontrak elektronik dapat dikelompokkan sebagai perikatan yang meiliki ancaman hukuman, karena apabila pelaku usaha tidak memenuhi kewajibannya maka konsumen berhak untuk mendapatkan ganti untung atas kerugian yang disebabkan oleh lalainya pelaku usaha dalam melakukan kewajibannya, begitu juga sebaliknya jika konsumen tidak memenuhi kewajibannya seperti yang diatur dalam kontrak elektronik tersebut ${ }^{7}$. Kontrak elektronik termasuk dalam jenis perjanjian tidak bernama, karena kontrak elektronik ini tidak diatur dalam Kitab Undang-Undang Hukum Perdata. Suatu perjanjian agar menjamin kepastian bagi para pihak mengenai keabsahan dari perjanjian tersebut, maka haruslah memenuhi syarat-syarat sahnya perjanjian yang diatur dalam Pasal 1320 Kitab UndangUndang Hukum Perdata ${ }^{8}$. Diketahui bahwa pada pasal 9 Undang-Undang No. 11 Tahun 2008 tentang Informasi dan Transaksi Elektronik dinyatakan bahwa pelaku usaha yang menawarkan produk melalui sistem elektronik haruslah menyediakan informasi yang lengkap dan benar berkaitan dengan syarat kontrak, produsen dan produk yang ditawarkan, akan tetapi dalam ketentuan ini tidak dijelaskan lebih lanjut syarat kontrak yang bagaimana yang dimaksudkan. Bahkan di dalam penjelasannya pun tidak mencantumkan dan menjelaskan lebih lengkap mengenai hal ini. Pada pasal 47 Peraturan Pemerintah No. 82 Tahun 2012 tentang Penyelenggaraan Sistem dan Transaksi Elektronik mencantumkan syarat syarat sahnya kontrak elektronik, yaitu terdapat kesepakatan para pihak, dilakukan oleh subjek hukum yang cakap atau yang berwenang mewakili sesuai dengan ketentuan peraturan perundang-undangan, terdapat hal tertentu dan objek transaksi tidak boleh bertentangan dengan peraturan perundang-undangan, kesusilaan dan ketertiban umum 9 Satu poin penting yang tidak dicantumkan secara jelas dalam ketentuan di atas adalah mengenai suatu sebab yang halal atau itikad baik, padahal seperti yang kita ketahui bahwa

\footnotetext{
${ }^{7}$ Budiana, N. (2018). KEABSAHAN KONTRAK ELEKTRONIK. Jurnal Analisis Hukum, 3.

${ }^{8}$ Syahrani, R. (2010). Seluk Beluk dan Asas-Asas Hukum Perdata. Bandung: PT.ALUMNI.

${ }^{9}$ Andira, L. C. (2020). Keabsahan Kontrak Elektronik Dalam Layanan Pinjam Meminjam Uang Berbasis Teknologi Informasi. Jurnal Ilmu kenotariatan, 10.
} 
itikad baik merupakan hal penting dalam suatu perjanjian yang dapat melindungi para pihak dari kerugian. Bahkan Penjelasan terhadap Peraturan Pemerintah No. 82 Tahun 2012 tentang Penyelenggaraan Sistem dan Transaksi Elektronik tidak menjelaskan lebih lanjut mengenai syarat-syarat sahnya kontrak elektronik ini.

Dalam hal jual beli online yang dilakukan melalui website biasanya terdapat button agree dan disagree yang dapat diklik oleh konsumen jika mereka menyetujui atau tidak menyetujui perjanjian yang ditawarkan. Di mana hal ini sangat mudah dilakukan oleh siapa saja dan oknum-oknum tertentu dapat menggunakan identitas orang lain untuk melakukan hal ini. Apalagi jual beli online tersebut dilakukan melalui media sosial seperti instagram, line dan whatsapp. Terlihat dengan jelas bahwa peraturan perundang-undangan mengenai informasi dan transaksi elektronik tidak menjamin kepastian hukum bagi para pihak khususnya pihak konsumen, karena pembuatan kontrak elektronik selalu didominasi oleh pelaku usaha, selain itu keadilanpun tidak tercipta karena kedudukan antara pelaku usaha dan konsumen tidak seimbang karena kepastian dan keadilan tidak tercapai maka masyarakat khususnya disini pihak konsumen tidak mendapatkan manfaat yang seharusnya dari ketentuan peraturan perundang-undangan ini.

Hal ini jelas sangat bertentangan dengan teori cita hukum yang dikemukakan oleh Gustav Radbruch, di mana cita hukum atau tujuan hukum adalah semata-mata untuk menciptakan keadilan, kepastian hukum serta hukum dapat berfungsi dan bermanfaat bagi masyarakat sehingga dapat berjalan dan mampu mempertahankan ketertiban. keadilan, kemanfaatan dan kepastian merupakan satu kesatuan yang saling melengkapi satu sama lain untuk menciptakan suatu sistem hukum yang positif ${ }^{10}$.

Teori cita hukum oleh Gustav Radbruch ini bertujuan untuk mewujudkan cita hukum (keadilan, kemanfaatan dan kepastian) sehingga dapat tercipta suatu sistem norma di mana norma satu dengan norma lainnya tidak berbenturan atau menimbulkan konflik, tidak bermakna kabur atau tidak terjadi kekosongan hukum.

Dalam Pembuatan Kontrak Elektronik Perlindungan Hukum Terhadap Konsumen terdapat pada para pihak yang terlibat dalam pembuatan kontrak elektronik biasanya adalah pelaku usaha dan konsumen. Sedangkan pemerintah berfungsi sebagai pengawas dalam penegakan hukum perlindungan konsumen ${ }^{11}$. Karena hal ini dianggap dapat mempersingkat waktu dan biaya, pelaku usaha biasanya menggunakan klausula baku dalam pembuatan kontrak elektronik. Klausula baku selalu ditentukan oleh pelaku usaha yang kemudian ditawarkan pada konsumen dan konsumen hanya memiliki dua pilihan, yaitu menyetujui seluruh klausula tersebut atau tidak sama sekali (take it or leave it) ${ }^{12}$. Hal ini jelas membuat posisi konsumen menjadi sangat lemah, terutama dalam transaksi jual beli online. Pasal 18 Undang-Undang No. 8 Tahun 1999 tentang Perlindungan Konsumen mengatur mengenai klausula-klausula baku yang dilarang untuk dicantumkan dalam perjanjian baku, salah satu klausula baku yang dilarang yang berkaitan dengan permasalahan

\footnotetext{
10 Tanya, B. L. (2013). Teori Hukum: Strategi Tertib Manusia Lintas Ruang dan Generasi. Yogyakarta: Genta Publishing.

11 Ranto, R. (2019). TINJAUAN YURIDIS PERLINDUNGAN HUKUM TERHADAP KONSUMEN DALAM TRANSAKSI JUAL BELI MELALUI MEDIA ELEKTRONIK. JURNAL ILMU HUKUM ALETHEA, 147.

${ }_{12}$ Kapoh, S. J. (2020). KAJIAN HUKUM PENERAPAN KONTRAK BAKU ELEKTRONIK PADA TRANSAKSI E COMMERCE. Lex Et Societatis Journal, 3
}

(c) Author(s). This work is licensed under a Creative Commons Attribution-NonCommercial-ShareAlike 4.0 International License. Published by Postgraduate Program, Master of Laws, Faculty of Law, Universitas Sebelas Maret, Indonesia 
pada jurnal ini adalah pada poin b yaitu menyatakan bahwa pelaku usaha berhak menolak penyerahan kembali barang yang dibeli konsumen. Banyak online shop terutama melalui media sosial mencantumkan klausula baku yang tidak sesuai dengan ketentuan di atas, tidak hanya online shop bahkan toko offlinepun banyak yang mencantumkan klausula baku seperti "barang yang sudah dibeli tidak dapat dikembalikan lagi" dan sebagainya. Kemudian bagaimana jika terjadi cacat dalam produk tersebut? Dalam jual beli online, konsumen tidak dapat seleluasa ketika berkunjung ke toko offline karena konsumen tidak mengetahui kualitas barang yang dipacking oleh pelaku usaha untuknya. Pelaku usahalah yang seharusnya dapat memeriksa semuanya dengan teliti dan memberikan barang dengan kualitas terbaik sesuai dengan informasi yang telah diberikan pada konsumen. Hal ini berkaitan erat dengan ketentuan cacat tersembunyi yang diatur dalam perjanjian konvensional. Pasal 1491 Kitab Undang-Undang Hukum Perdata menyatakan bahwa pelaku usaha berkewajiban untuk menjamin 2 hal ini pada konsumennya yaitu, penguasaan barang yang dijual itu secara aman dan tenteram dan tidak ada cacat tersembunyi pada barang tersebut. Pasal 1504 Kitab Undang-Undang Hukum Perdata menyatakan bahwa pelaku usaha harus menanggung barang tersebut terhadap cacat tersembunyi. Namun jika terhadap cacat yang terlihat dan dapat diketahui oleh pembeli, maka pelaku usaha tidak wajib menjamin barang tersebut, hal ini diatur dalam ketentuan Pasal 1505 Kitab UndangUndang Hukum Perdata. Jika dikaitkan dengan transaksi jual beli online segala macam barang yang dikirimkan oleh pelaku usaha tanpa disertai informasi yang jelas dari pelaku usaha, jika barangnya mengalami cacat maka itu akan masuk dalam kategori cacat tersembunyi. Hal ini dikarenakan konsumen dalam jual beli online tidak dapat melihat sendiri kondisi nyata dari barang yang dipilihkan oleh pelaku usaha untuk dikirimkan kepadanya. Pasal 1507 Kitab Undang-Undang Hukum Perdata menyatakan bahwa dalam hal-hal tersebut dalam Pasal 1504 dan 1505, pembeli dapat memilih akan mengembalikan barangnya sambil menuntut kembali uang harga pembelian atau akan tetap memiliki barang itu sambil menuntut kembali sebagian dari uang pembelian sebagaimana ditentukan oleh hakim setelah mendengar ahli tentang itu. Jadi dapat kita simpulkan bahwa ketentuan mengenai cacat tersembunyi ini juga dapat diaplikasikan pada kontrak elektronik.

Ketentuan mengenai klausula baku yang tidak terawasi ini justru akan memberikan dampak yang merugikan konsumen, apalagi dalam pembuatan kontrak elektronik selain posisi konsumen menjadi sangat lemah, kepentingan konsumenpun menjadi seakan-akan terabaikan. Melihat pada teori perlindungan hukum menurut Philipus M. Hadjon yaitu perlindungan hukum bagi rakyat sebagai tindakan pemerintah yang bersifat preventif dan represif. Perlindungan hukum yang preventif bertujuan untuk mencegah terjadinya sengketa, yang mengarahkan tindakan pemerintah bersikap hati-hati dalam pengambilan keputusan berdasarkan diskresi dan perlindungan yang represif bertujuan untuk menyelesaikan terjadinya sengketa, termasuk penanganannya di lembaga peradilan. (Hadjon, 2018). Perlindungan hukum bila dijelaskan secara harfiah dapat menimbulkan banyak persepsi. Perlindungan hukum dapat berarti perlindungan yang diberikan terhadap hukum agar tidak ditafsirkan berbeda dan tidak dicederai oleh aparat penegak hukum dan juga dapat berarti perlindungan yang diberikan oleh hukum terhadap sesuatu ${ }^{13}$.

Seharusnya konsumen mendapatkan perlindungan hukum dari kerugian yang ditimbulkan oleh transaksi jual beli online. Dalam ketentuan Pasal 23 Undang-Undang No.

${ }^{13}$ Mertokusumo, S. (2000). PENEMUAN HUKUM. BANDUNG: CITRA ADITYA BAKTI. 
11 Tahun 2008 tentang Informasi dan Transaksi Elektronik dimuat mengenai pendaftaran nama domain, di mana menurut Wikipedia nama domain adalah nama yang diberikan untuk mengidentifikasi nama server komputer seperti web server atau email server di jaringan internet ataupun komputer. Jadi peraturan ini hanyalah mencakup pada akun-akun website saja, tidak termasuk media sosial. Karena risiko-risiko yang ditimbulkan oleh jual beli online, pelaku usaha haruslah mendaftarkan usaha onlinenya melalui badan hukum tertentu yang dibentuk pemerintah. Selain itu penggunaan media sosial dapat dibatasi hanya untuk mempromosikan usaha dari pelaku usaha saja.

\section{CONCLUSION}

Pasal 9 Undang-Undang No. 11 Tahun 2008 tentang Informasi dan Teknologi Elektronik, sayangnya tidak mengatur lebih jelas mengenai syarat kontrak yang seperti apa yang dimaksudkan oleh pengaturan ini. Bahkan setelah peraturan ini direvisi dengan Undang-Uundang No. 19 Tahun 2016 tentang Perubahan Atas Undang-Undang No. 11 Tahun 2008 tentang Informasi dan Teknologi Elektronik, tidak juga diatur lebih lanjut mengenai syarat kontrak ini. Kemudian Pasal 47 Ayat 2 Peraturan Pemerintah No. 82 Tahun 2012 tentang Penyelenggaraan Sistem dan Transaksi Elektronik mencantumkan mengenai syarat sahnya kontrak elektronik, namun poin yang sangat penting berupa sebab atau kausa yang halal tidak dicantumkan sehingga hal ini menimbulkan ketidakpastian pada masyarakat. Teori Cita Hukum oleh Gustav Radbruch menyatakan bahwa hukum diciptakan agar dapat mewujudkan kepastian, kemanfaatan dan keadilan bagi masyarakat. Namun pengaturan mengenai syarat sahnya suatu kontrak elektronik tidak dapat memenuhi cita-cita hukum. Dalam pembuatan kontrak elektronik, pelaku usaha seringkali mencantumkan klausula baku di dalamnya. Meskipun dalam UndangUndang No. 8 Tahun 1999 tentang Perlindungan Konsumen mengatur mengenai ketentuan klausula baku, namun masih belum dapat melindungi konsumen dalam pembuatan kontrak elektronik. Berdsarkan sejumlah risiko serta cara pembuatan kontrak elektronik, posisi yang lemah selalu ada pada konsumen. Semenjak media sosial mewabah dan pelaku usahapun menggunakan media sosial untuk melakukan transaksi elektronik, posisi konsumen menjadi semakin lemah. Klausula baku yang dibuat oleh pelaku usaha seringkali memojokkan posisi dari konsumen tersebut.

\section{REFERENCES}

Andira, L. C. (2020). Keabsahan Kontrak Elektronik Dalam Layanan Pinjam Meminjam Uang Berbasis Teknologi Informasi. Jurnal Ilmu kenotariatan, 10.

Arista, O. (2013). EFEKTIVITAS UNDANG-UNDANG INFORMASI DAN TRANSAKSI ELEKTRONIK DI INDONESIA. UNS Journal of Law, 139.

Budiana, N. (2018). KEABSAHAN KONTRAK ELEKTRONIK. Jurnal Analisis Hukum, 3.

(C) Author(s). This work is licensed under a Creative Commons Attribution-NonCommercial-ShareAlike 4.0 International License. Published by Postgraduate Program, Master of Laws, Faculty of Law, Universitas Sebelas Maret, Indonesia 
Budiono, H. (2010). Ajaran Umum Hukum Perjanjian dan penerapannya. Bandung: Citra Aditya.

ekarini, M. A. (2014). "Eksistensi Asas Kebebasan Berkontrak Berkaitan Dengan Klausula Eksonerasi Dalam Perjanjian Baku. Kertha Semaya: Journal of law, 3.

Hadjon, P. M. (2018). Perlindungan Hukum Bagi Rakyat Indonesia. Surabaya: PT.BINA ILMU.

Kapoh, S. J. (2020). KAJIAN HUKUM PENERAPAN KONTRAK BAKU ELEKTRONIK PADA TRANSAKSI E COMMERCE. Lex Et Societatis Journal, 3.

Latumahina, R. E. (2015). Aspek-aspek Hukum Dalam Transaksi Perdagangan Secara . Jurnal GEMA AKTUALITA , 43.

Man Suparman Sastrawidjaja. (2002). Perjanjian Baku Dalam Aktivitas Dunia Maya,. Jakarta: elips .

Manap, M. A. (2018). Kontrak Elektronik: Isu dan Penyelesaian Undang-Undang . Journal of law and goverment, 64.

Mertokusumo, S. (2000). PENEMUAN HUKUM. BANDUNG: CITRA ADITYA BAKTI.

Putri, W. S. (2018). KEABSAHAN KONTRAK ELEKTRONIK DALAM TRANSAKSI ECOMMERCE DITINJAU DARI HUKUM PERIKATAN. JURNAL UNDIKNAS, 301.

Ranto, R. (2019). TINJAUAN YURIDIS PERLINDUNGAN HUKUM TERHADAP KONSUMEN DALAM TRANSAKSI JUAL BELI MELALUI MEDIA ELEKTRONIK. JURNAL ILMU HUKUM ALETHE $A, 147$.

Syahrani, R. (2010). Seluk Beluk dan Asas-Asas Hukum Perdata. Bandung: PT.ALUMNI.

Tanya, B. L. (2013). Teori Hukum: Strategi Tertib Manusia Lintas Ruang dan Generasi. Yogyakarta: Genta Publishing.

(C) Author(s). This work is licensed under a Creative Commons Attribution 4.0 International License .

Published by Postgraduate Program, Master of Laws, Faculty of Law, Universitas Sebelas Maret, Indonesia 